\title{
Assessment of Thyrotropin-Releasing Hormone and Thyrotropin Reserve in Man
}

\author{
Peter A. Singer and John T. Nicoloff \\ From the Department of Medicine, University of Southern California School of \\ Medicine and the Los Angeles County-USC Medical Center, \\ Los Angeles, California 90033
}

\begin{abstract}
A в S T R A C T Endogenous thyrotropin-releasing hormone $(\mathrm{TRH})$ reserve and pituitary thyrotropin (TSH) reserve were assessed in four normal subjects, three patients post-cryohypophysectomy, one patient with a hypothalamic lesion secondary to trauma, and four patients with Sheehan's syndrome. TSH reserve was determined by the immunoassayable $\mathrm{TSH}$ response to 500 $\mu \mathrm{g} \mathrm{TRH}$ given i.v. ( $\mathrm{TRH}$ stimulation test). TRH reserve was assessed by the rebound response in thyroidal iodine release (TIR) following withdrawal of pharmacologic doses of prednisolone (glucocorticoid withdrawal test). When compared with normals, the postcryohypophysectomy patients demonstrated parallel impairment of TRH stimulation and glucocorticoid withdrawal testing. The patient with the hypothalamic lesion and the four patients with Sheehan's syndrome all had normal TRH stimulation tests, indicating adequate $\mathrm{TSH}$ reserve capacity, yet had abnormal glucocorticoid withdrawal tests, indicative of impairment in endogenous $\mathrm{TRH}$ reserve or neurohumoral transport. Three of the patients (hypothalamic injury and two Sheehan's) with impaired TRH reserve were euthyroid.

The following conclusions were reached: (a) A combination of the TRH stimulation test and glucocorticoid withdrawal test may allow for differentiation between pituitary and suprahypophyseal disorders. (b) Certain cases of Sheehan's syndrome appear to have impaired endogenous TRH reserve or transport. (c) Euthyroidism can be maintained in spite of diminished $\mathrm{TRH}$ reserve.
\end{abstract}

\section{INTRODUCTION}

The availability of synthetic thyrotropin-releasing hormone $(\mathrm{TRH})^{1}$ for clinical investigation has led to the

Received for publication 13 November 1972 and in revised form 8 January 1973.

${ }^{1}$ Abbreviations used in this paper: KGS, ketogenic ster- report of numerous studies concerning the assessment of pituitary thyrotropin ( $\mathrm{TSH}$ ) reserve capacity in normal man. TRH administration has been employed in the evaluation of TSH reserve in patients with Graves' disease $(1,2)$, primary hypothyroidism $(1,3,4)$, monotrophic TSH deficiency (5), and panhypopituitarism (3, $4,6)$. Much interest has also been recently directed at the separation of secondary hypothyroidism into pituitary and hypothalamic causes. The patient with hypothalamic hypothyroidism is presently defined as having subnormal circulating thyroid hormone levels associated with normal responses of the thyroid and pituitary glands to exogenous TSH and TRH stimulation respectively $(7,8)$. Presumably these patients have a deficiency in endogenous hypothalamic TRH secretion. This is a conclusion which is reached by indirection however, for as yet, no direct measurement of endogenous TRH secretory capacity is possible. Thus, a diagnosis of hypothalamic hypothyroidism is now established by excluding thyroidal and pituitary etiologies.

Recently we have proposed a qualitative method for assessing endogenous $\mathrm{TRH}$ and $\mathrm{TSH}$ reserve in man (9). This method is based on the observation that glucocorticoid administration in pharmacologic doses will acutely inhibit endogenous TRH secretion without directly affecting other facets of pituitary or thyroid function. Following the withdrawal of glucocorticoid administration, there is an apparent surge in TRH secretion leading to a measurable augmentation in TSH release and secondarily in thyroidal iodine release (TIR). The purpose of the present investigation is to report the usefulness of the surge in TIR following glucocorticoid withdrawal in conjunction with the assessment of pituitary $\mathrm{TSH}$ reserve capacity by exogenous TRH adminis-

oid ; RAIU, radioactive iodine uptake; $\mathrm{T}_{4}$, thyroxine; TIR, thyroidal iodine release; $\mathrm{TRH}$, thyrotropin releasing hormone; TSH, thyrotropin. 
TABLE I

Endocrine Function Tests in Patient Groups

\begin{tabular}{|c|c|c|c|c|c|c|c|c|c|c|c|c|}
\hline \multirow[b]{2}{*}{ Patients } & \multirow[b]{2}{*}{ Age } & \multirow[b]{2}{*}{ Sex } & \multirow[b]{2}{*}{$\begin{array}{c}\text { Urinary } \\
\text { gonadotropins }\end{array}$} & \multicolumn{2}{|c|}{$\begin{array}{l}\text { Plasma growth } \\
\text { hormone }\end{array}$} & \multicolumn{3}{|c|}{ Urinary $17 \mathrm{KGS}$ excretion } & \multirow[b]{2}{*}{ Serum T $₫$} & \multirow[b]{2}{*}{ Free $T_{4} \S$} & \multicolumn{2}{|c|}{$\begin{array}{l}\text { Thyroidal } \\
24 \mathrm{hr} \text { RAIU }\end{array}$} \\
\hline & & & & $\begin{array}{l}\text { Base } \\
\text { line }\end{array}$ & $\begin{array}{l}\text { Maxi- } \\
\text { mum* }\end{array}$ & $\begin{array}{l}\text { Base } \\
\text { line }\end{array}$ & $\begin{array}{c}\text { After } \\
\text { methopyrapone }\end{array}$ & $\begin{array}{l}\text { After } \\
\text { ACTH }\end{array}$ & & & $\begin{array}{l}\text { Before } \\
\text { TSH }\end{array}$ & $\begin{array}{l}\text { After } \\
\text { TSH }\end{array}$ \\
\hline \multicolumn{3}{|c|}{ Normal Subjects } & $m U / 2+h r$ & $n g / m l$ & & \multicolumn{2}{|r|}{$m g / 24 h$} & & $\mu g / 100 \mathrm{ml}$ & $n g / 100 \mathrm{ml}$ & \multicolumn{2}{|c|}{$\%$} \\
\hline C. C. & 42 & $\mathrm{~F}$ & $>100$ & 2.3 & 11.3 & 8.3 & 42.9 & - & 6.8 & 2.0 & - & - \\
\hline T. C. & 16 & $\mathrm{~F}$ & $16-50$ & $<2.0$ & 6.6 & 8.1 & 38.2 & - & 5.1 & 1.5 & 一 & - \\
\hline B. P. & 33 & $\mathrm{~F}$ & $16-50$ & $<2.0$ & 9.0 & 7.5 & 55.1 & - & 6.7 & 2.0 & - & - \\
\hline H. F. & 30 & $\mathrm{~F}$ & $16-50$ & 1.1 & 7.1 & 6.9 & 49.4 & - & 5.8 & 1.6 & - & - \\
\hline \multicolumn{13}{|c|}{ Post-cryohypophysectomy patients } \\
\hline J. Z. & 37 & $\mathrm{M}$ & $6-16$ & 2.1 & 3.8 & 7.8 & 20.4 & - & 2.2 & 0.8 & 5 & - \\
\hline F.M. & 35 & M & 6 & 1.5 & 1.2 & 3.9 & 4.5 & - & 5.2 & 2.0 & 11 & - \\
\hline C. S. & 32 & $\mathrm{~F}$ & 6 & 1.5 & 2.8 & 4.1 & 16.4 & - & 1.4 & 0.7 & 4 & - \\
\hline \multicolumn{13}{|c|}{ Hypothalamic injury patient } \\
\hline L. L. & 23 & $\mathrm{M}$ & $16-50$ & 3.6 & 52.0 & 6.1 & 15.8 & - & 5.2 & 1.4 & 22 & - \\
\hline \multicolumn{13}{|c|}{ Sheehan's syndrome patients } \\
\hline J. B. & 25 & $\mathrm{~F}$ & $16-50$ & $<2.0$ & $<2.0$ & 4.2 & 5.9 & 24.1 & 5.4 & 1.4 & 17 & - \\
\hline D. C. & 44 & $\mathrm{~F}$ & $<6$ & 0.2 & 1.9 & 1.1 & 1.6 & 8.1 & 3.0 & 1.2 & 21 & - \\
\hline P. T. & 23 & $\mathrm{~F}$ & $<6$ & 2.0 & $<2.0$ & 4.3 & 6.6 & 22.3 & 2.0 & 0.9 & 8 & 19 \\
\hline V.N. & 29 & $\mathrm{~F}$ & $16-50$ & $<2.0$ & $<2.0$ & 2.3 & 2.8 & 26.7 & 2.0 & 0.7 & 17 & 31 \\
\hline
\end{tabular}

* Following insulin-induced hypoglycemia.

$\ddagger$ Expressed as $\mathrm{T}_{4}$ iodine (normal values: 3.0-7.0 $\mu \mathrm{g} / 100 \mathrm{ml}$ ) (performed by Bio-Science Laboratories, Van Nuys, Calif.).

$\S$ Normal values: $1.0-2.3 \mathrm{ng} / 100 \mathrm{ml}$ (performed by Bio-Science Laboratories).

tration as a more definitive means for distinguishing between pituitary and hypothalamic derangements in thyroid hormone regulation.

\section{METHODS}

\section{Study groups}

12 subjects were included in this study (see Table I) : Four normal subjects had been referred to our Center for evaluation of possible pituitary lesions but were found to be free of disease. Of the normals, C. C. was referred for evaluation of headaches and oligomenorrhea; T. C. was referred for amenorrhea, which during 6 mo of observation, spontaneously cleared without specific therapy; H. F. was evaluated for postpartum oligomenorrhea which subsequently cleared; and B. P. was referred to suspected visual field impairment which by more extensive examination was found not to be present. Of the other study patients, three had undergone cryohypophysectomy for acromegaly, one patient had sustained a traumatic hypothalamic injury manifested later by a disordered thirst mechanism with hypernatremia, and four patients had Sheehan's syndrome. Diagnoses in individual cases were made clinically and were confirmed by appropriate laboratory testing. All studies were performed on the Clinical Research Center of the Los Angeles County-USC Medical Center. Patients who had been taking thyroid medication were withdrawn from thyroid hormone for at least $4 \mathrm{wk}$ prior to testing.

\section{Pituitary testing}

Growth hormone reserve was determined by the rise in plasma growth hormone in response to insulin-induced hypo- glycemia (10). Growth hormone determinations were performed by a modification of the radioimmunoassay method of Greenwood and Hunter (11). ACTH reserve was assessed by the rise in the $24 \mathrm{~h}$ urinary ketogenic steroid (KGS) excretion following the administration of methopyrapone given orally on a schedule of $750 \mathrm{mg}$ every $4 \mathrm{~h}$ for a 2 day period. Urinary KGS excretion was determined by the method of Rutherford and Nelson (12). When the methopyrapone test was abnormal, the adequacy of adrenal function was verified by measuring urinary 17KGS excretion in response to the intravenous administration of synthetic ACTH. Pituitary gonadotropins were assessed by measurement of urinary bioassayable gonadotropins (13).

\section{Thyroid testing procedures}

Serum TSH values were determined by the double antibody radioimmunoassay technique described by Odell, Wilber, and Utiger (14). Serum thyroxine was measured by the competitive protein binding method of Murphy and Pattee (15) and free thyroxine estimates by the method of Sterling and Brenner (16) (performed by Bio-Science Laboratories, Van Nuys, Calif). 24-h thyroidal radioactive iodine uptake measurements (RAIU) before and following TSH stimulation were performed in selected cases.

\section{Thyroidal iodine release (TIR) method}

A dual iodine isotopic release method was used to measure changes in TIR. This method has been described in detail in previous reports $(17,18)$. To summarize briefly, each subject was administered carrier-free ${ }^{125} \mathrm{I}$ orally in order to label the thyroid gland endogenously. The dose of ${ }^{125} \mathrm{I}$ administered was calculated on the basis of RAIU 


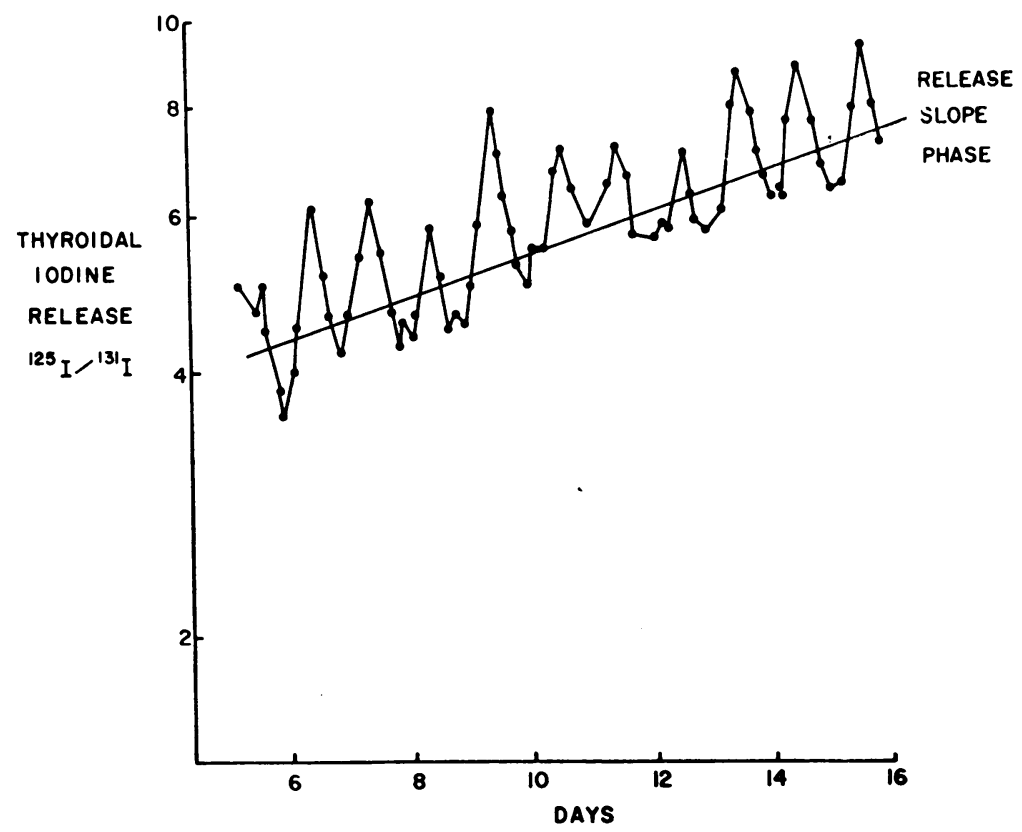

Figure 1 A thyroidal iodine release slope in a normal euthyroid subject is depicted. The solid line is drawn through the base-line control slope. The notation "days" on the abscissa represents time following [ $\left.{ }^{125} \mathrm{I}\right]-$ and $\left[{ }^{131} \mathrm{I}\right] \mathrm{T}_{4}$ administration. Each numeral coincides with midnight.

measurements so that $10-15 \mu \mathrm{Ci}$ would be delivered to the thyroid gland. $50 \mu \mathrm{Ci}$ of $\left[{ }^{121} \mathrm{I}\right]$ thyroxine $\left(\mathrm{T}_{4}\right)$ (specific activity was greater than $40 \mu \mathrm{Ci} / \mu \mathrm{g}$ at time of administration) was then given intravenously to serve as a reference isotope. The site of measurement of the thyroid release products was the urine. Urinary ratios of ${ }^{125} \mathrm{I} /{ }^{131} \mathrm{I}$ were used to detect changes in TIR. Since $T_{4}$ is deiodinated at a relatively constant rate (19), alterations in renal clearance do not change ${ }^{125} \mathrm{I} /{ }^{131} \mathrm{I}$ ratio values, and therefore any changes in ratio values would reflect alterations in TIR. Fig. 1 depicts a normal TIR release slope following equilibration of the isotopes. This predictable logarithmic linear slope we have termed the release slope phase of TIR. All studies in this investigation were performed during this phase. Superimposed on this linear slope are daily variations in TIR, which are a reflection of the normal circadian variations in serum TSH (9).

\section{Study protocol}

Glucocorticoid withdrawal testing. After a base-line TIR slope had been established, each subject was administered $20 \mathrm{mg}$ of prednisolone orally every $8 \mathrm{~h}$ for 3 days. Glucocorticoids were then withdrawn and the response of TIR measured for an additional 7-8 days until the presuppression base-line slope had been reestablished.

TRH stimulation test. Following completion of the glucocorticoid withdrawal test, each subject was administered $500 \mu \mathrm{g}$ of synthetic TRH in $5 \mathrm{ml}$ of sterile saline over a $15-30 \mathrm{~s}$ time interval. $10 \mathrm{ml}$ of blood was obtained by an indwelling 19 gauge scalp vein needle at $-30 \mathrm{~min}, 0 \mathrm{~min}$, $+15 \mathrm{~min},+20 \mathrm{~min},+30 \mathrm{~min},+45 \mathrm{~min},+60 \mathrm{~min}$, and +120 min following TRH administration. The blood was centrifuged shortly after collection and the sera separated and frozen until TSH determinations were performed.

\section{RESULTS}

Table I summarizes the endocrine function tests in both the normal subjects and the patient groups. Fig. 2 illustrates the effects of glucocorticoid administration and withdrawal on TIR in the four normal subjects. Following administration of prednisolone, there is normally a rapid suppression of TIR, which is reflected by a decrease in ${ }^{125} \mathrm{I} /{ }^{131} \mathrm{I}$ ratio values. Within $12-24 \mathrm{~h}$ following withdrawal of prednisolone, there is a marked surge and overshoot in TIR with resumption of the original release slope within 4-8 days. The linear interrupted line connects the pre-glucocorticoid suppression and postglucocorticoid withdrawal base-line TIR slopes. A similar pattern of suppression and prompt rebound and overshoot following withdrawal of glucocorticoids has been present in all of the more than 20 normal subjects whom we have studied in this manner (9). Note that in subject $H$. F. there is suppression of TIR below the base line 4 days following glucocorticoid withdrawal, lasting until 8 days post-steroid withdrawal before the control release slope is reestablished. A similar oscillation pattern below baseline following withdrawal of glucocorticoid has been noted in several of the other normal subjects we have studied.

Site and nature of glucocorticoid suppression. Present evidence suggests that glucocorticoids suppress hypothalamic release of TRH. The studies of Wilber and 


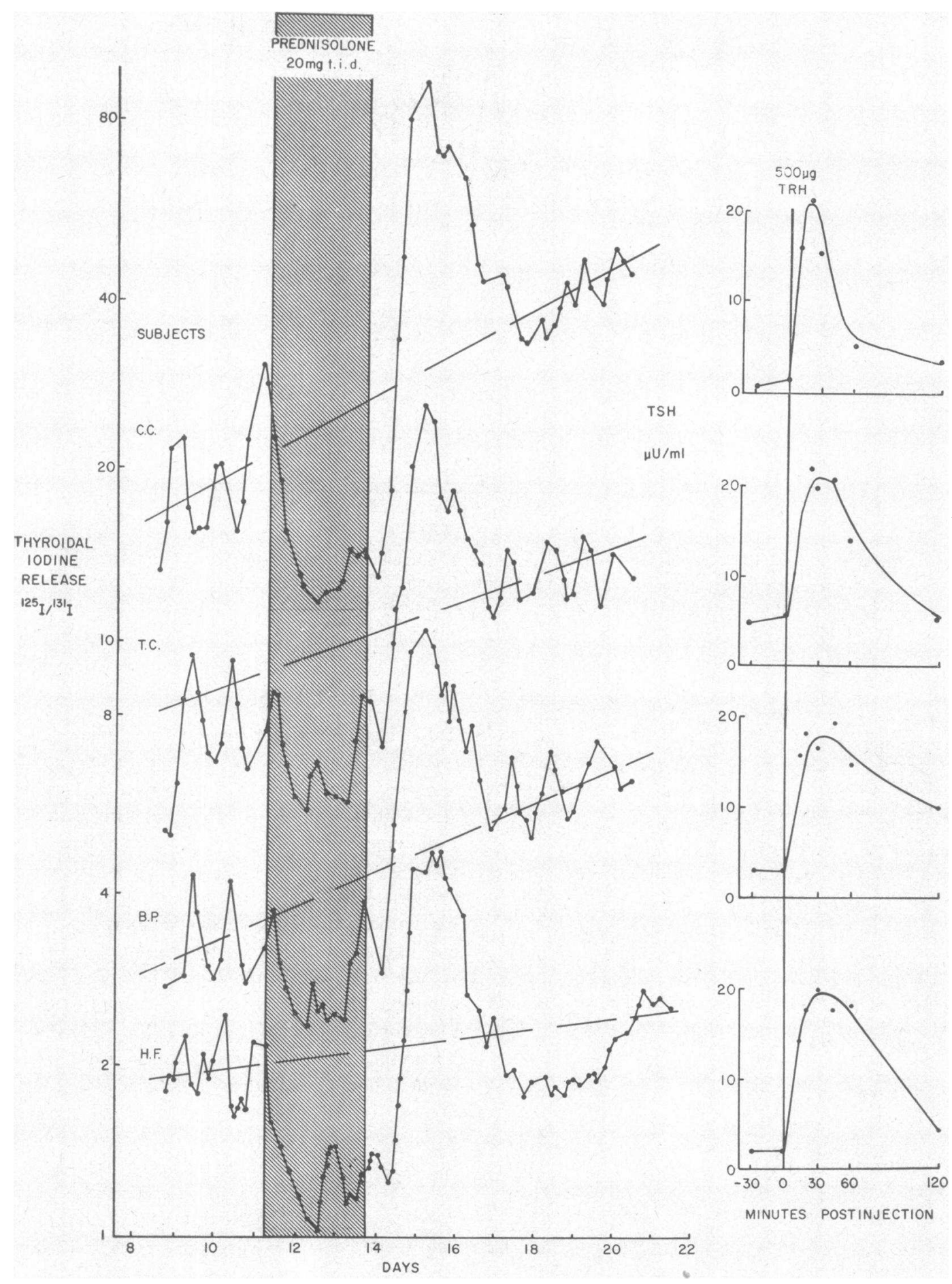

FIGURE 2 The effects of glucocorticoid administration and withdrawal on TIR in normal euthyroid subjects is shown. The broken line is drawn through the base-line control TIR slopes. Also shown are the TSH responses to i.v. administered synthetic TRH. The notation "days" on the abscissa represents time following [ $\left.{ }^{125} \mathrm{I}\right]-$ and $\left.{ }^{[181} \mathrm{I}\right] \mathrm{T}_{4}$ administration. Each numeral coincides with midnight. Prednisolone administered every $8 \mathrm{~h}$. 


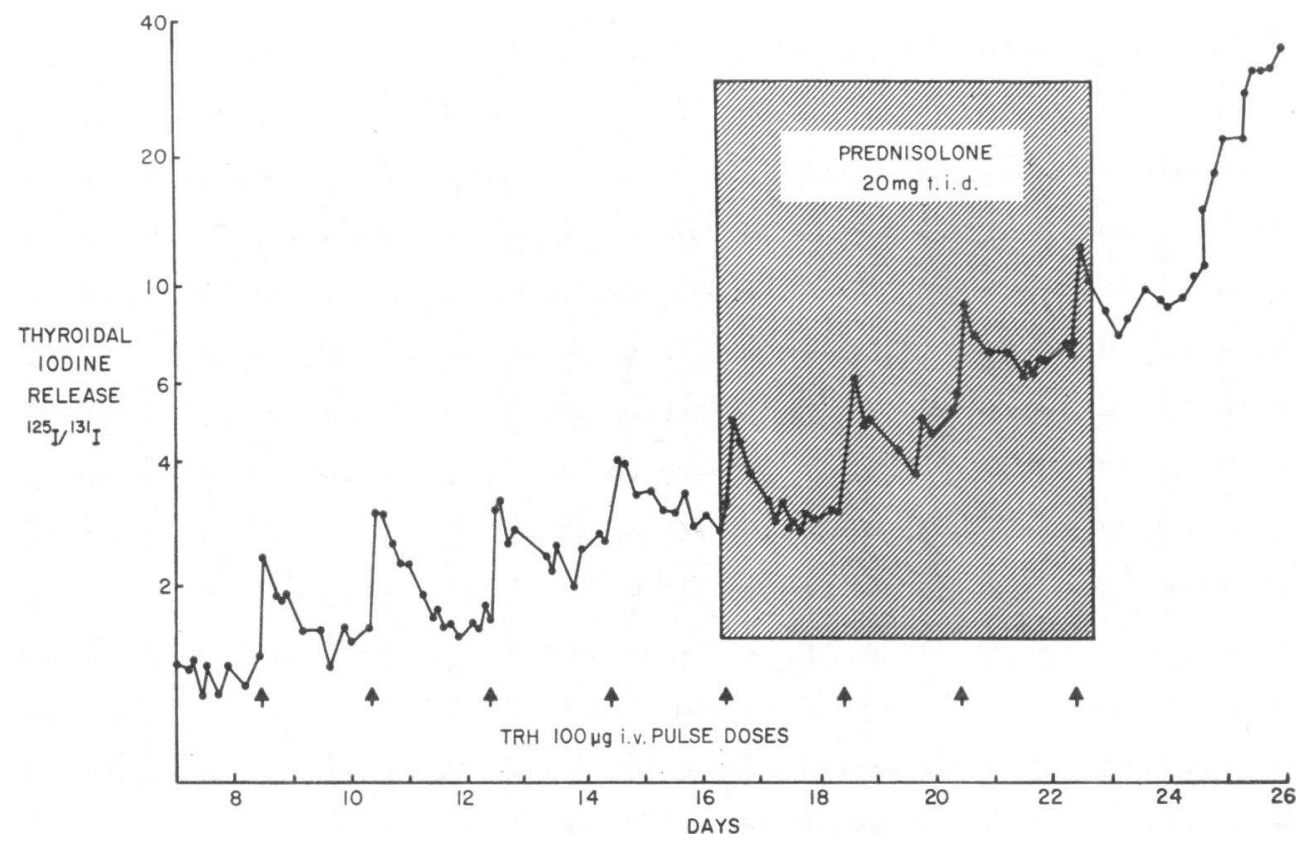

FIGURE 3 The TIR response to repetitive doses of i.v. TRH are shown in a-normal euthyroid subject before and during administration of pharmacological doses of glucocorticoids (depicted by the shaded area). The notation "days" on the abscissa represents time following $\left[{ }^{125} \mathrm{I}\right]$ - and $\left[{ }^{131} \mathrm{I}\right] \mathrm{T}_{4}$ administration. Each numeral coincides with midnight. Prednisolone administered every $8 \mathrm{~h}$.

Utiger (20) in the rat have shown that normal TSH responsiveness to exogenous TRH was maintained during a period of glucocorticoid administration, thus eliminating the anterior pituitary gland as the site of glucocorticoid suppression. We have confirmed these findings in man, as shown in Fig. 3, which illustrates that repetitive doses of synthetic TRH before and during a period of glucocorticoid administration produced similar responses in TIR. Thus, acutely, glucocorticoid administration appears not to significantly alter pituitary responsiveness to exogenous and presumably endogenous TRH stimulation. However, with chronic glucocorticoid administration, some reduction in pituitary TSH responsiveness to TRH administration has been reported (21). It seems then that the rebound in TIR following glucocorticoid withdrawal is mediated via an increase in endogenous TRH release. Thus, the sudden withdrawal of glucocorticoids, or what we have termed the "glucocorticoid withdrawal test" would appear to offer an indirect assessment of endogenous TRH reserve capacity. Because of the indirect nature of the methods employed, it becomes apparent that the glucocorticoid withdrawal test can serve as a measure of TRH reserve only when an intact pituitary-thyroid axis is present. Also depicted in Fig. 2 are the TSH responses to intravenously administered synthetic TRH in the normal control subjects. The TSH values are commensurate with those obtained in normal subjects by other workers employing similar doses of TRH. The dose of $500 \mu \mathrm{g}$ of TRH was used in the present study since previous work has shown that this is the maximal stimulating dose of pituitary TSH reserve capacity $(3,22)$.

Glucocorticoid withdrawal and TRH stimulation tests in patients with pituitary lesions. In order to test the hypothesis that diminished endogenous TSH reserve should be reflected by both abnormal glucocorticoid withdrawal and TRH stimulation tests, three patients who had undergone cryohypophysectomy for acromegaly were studied. The degree and severity of pituitary insufficiency in this group varied (see Table I). Fig. 4 demonstrates the loss of overshoot in TIR and a rather slow return to the base-line release slope following glucocorticoid withdrawal in all three of these subjects. While some overshoot is observed in patient J. Z., the degree is small and delayed compared with the normal subjects depicted in Fig. 2. Also noted are the markedly impaired TSH responses to synthetic TRH administration. It is apparent, however, that in spite of the pituitary unresponsiveness to exogenous TRH, there is some suppression of TIR following glucocorticoid administration. This would imply that some TSH reserve remains, and that this residual TSH secretion can be further diminished by the suppressive effect of glucocorticoids on hypothalamic TRH. Also noteworthy is that one of the sub- 


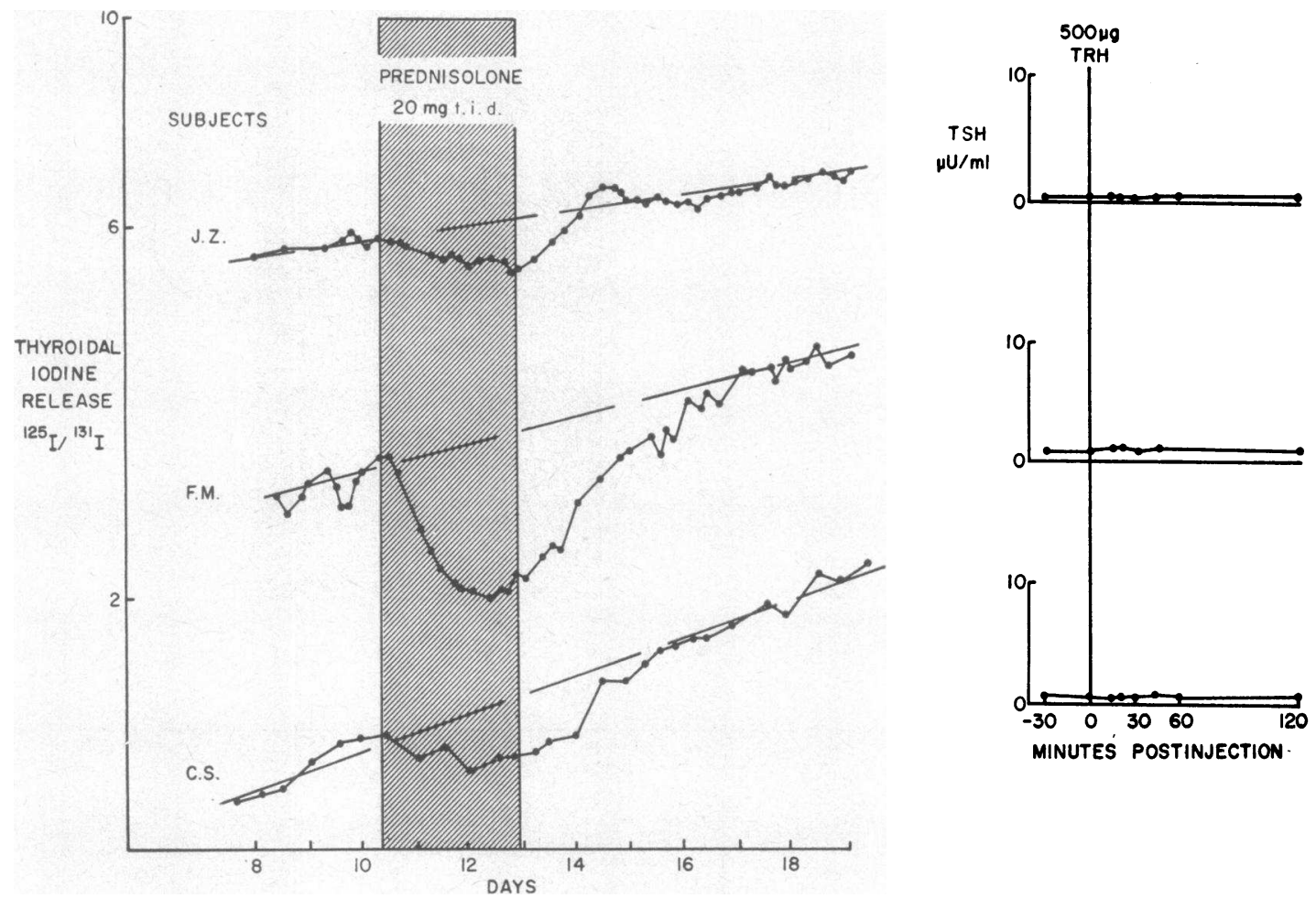

FIGURE 4 TIR rebound following glucocorticoid withdrawal, as well as TSH response to i.v. TRH, is noted to be impaired in patients with primary pituitary insufficiency. The notation "days" on the abscissa represents time following [ $\left.{ }^{125} \mathrm{I}\right]-$ and $\left[{ }^{131} \mathrm{I}\right] \mathrm{T}_{4}$ administration. Each numeral coincides with midnight. Prednisolone administered every $8 \mathrm{~h}$.

jects, F. M., is euthyroid. Thus it would also appear that a euthyroid state can be maintained in the presence of markedly diminished TSH reserve. The results of this study then would indicate that patients with primary pituitary insufficiency exhibit the expected parallel impairment in glucocorticoid withdrawal and TRH stimulation tests, and that a normal glucocorticoid rebound requires intact pituitary TSH secretion.
Study of a patient with hypothalamic lesion. Fig. 5 depicts a study performed on a 23-yr old male who had sustained a traumatic hypothalamic injury 5 yr earlier. This patient was clinically and chemically euthyroid. Noted is the abnormal glucocorticoid withdrawal test and the normal TSH response to TRH administration. While there is some TIR above the base line following glucocorticoid withdrawal, clearly the

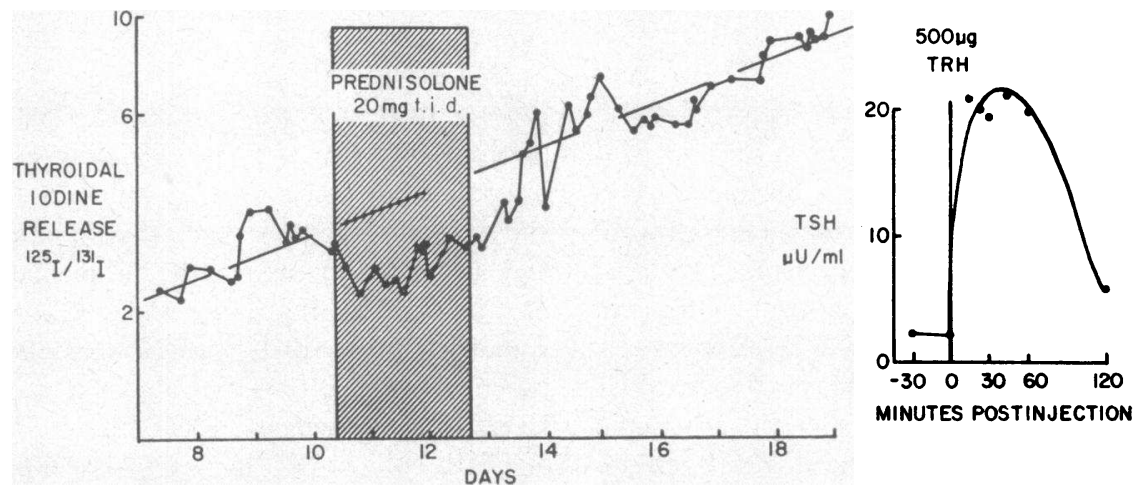

FIgURE 5 The abnormal TIR response to glucocorticoid withdrawal is contrasted to the normal response to i.v. TRH in this patient with known hypothalamic lesion. The notation "days" on the abscissa represents time following [ $\left.{ }^{125} \mathrm{I}\right]-$ and $\left[{ }^{131} \mathrm{I}\right] \mathrm{T}_{4}$ administration. Each numeral coincides with midnight. Prednisolone administered every $8 \mathrm{~h}$. 

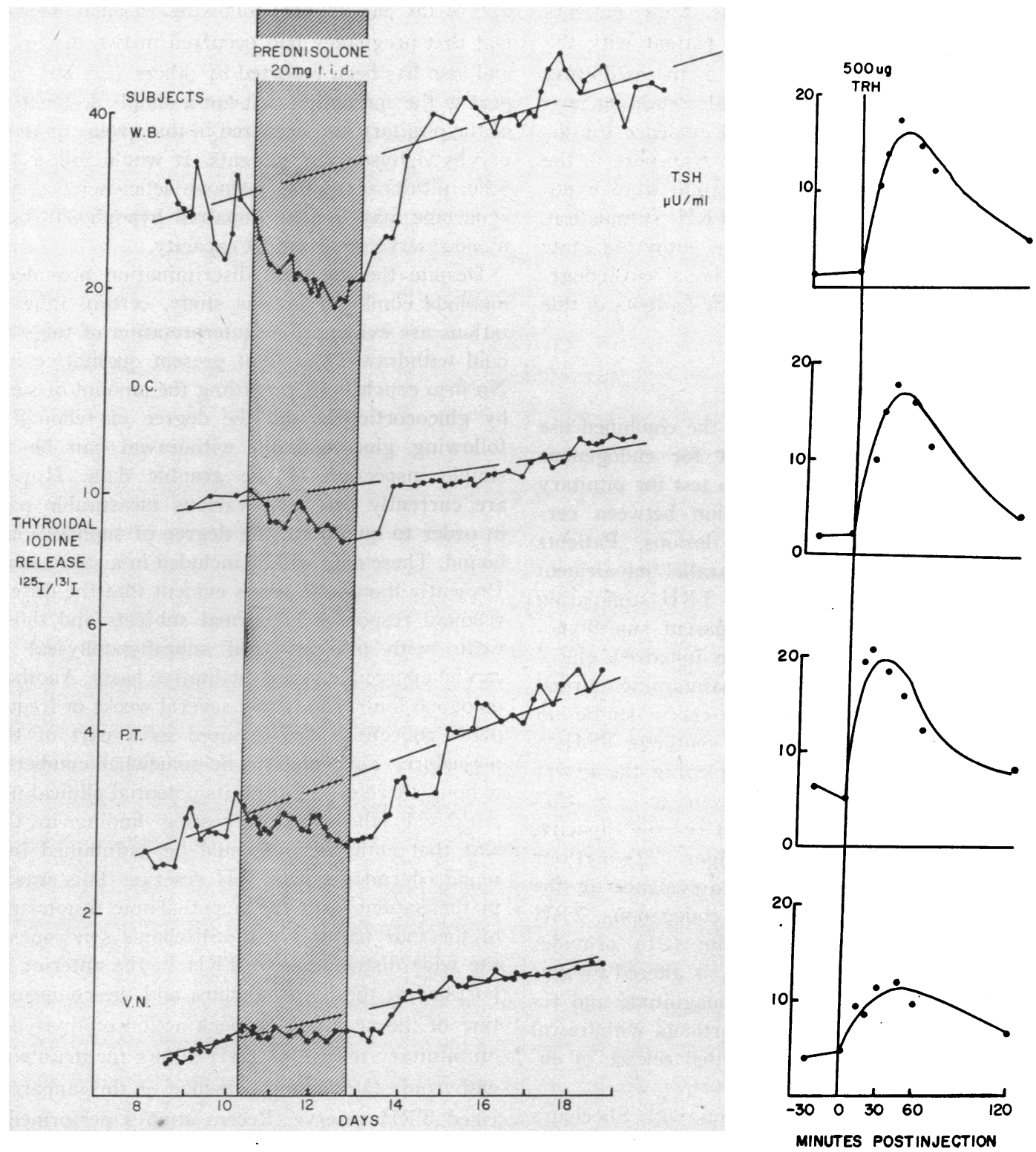

FIGURE 6 Glucocorticoid withdrawal and TRH stimulation responses in four patients with Sheehan's syndrome are depicted. Noted is that the TIR response to glucocorticoid withdrawal is abnormal, while TSH responsiveness to TRH is intact. The notation "days" on the abscissa represents time following [ $\left.{ }^{125} \mathrm{I}\right]$ - and [ $\left.{ }^{131} \mathrm{I}\right] \mathrm{T}_{4}$ administration. Each numeral coincides with midnight. Prednisolone administered every $8 \mathrm{~h}$.

response is blunted when compared to the normal subjects. This patient then displays a pattern consistent with diminished endogenous TRH reserve capacity, while retaining normal pituitary TSH reserve. This is at variance with the parallel impairment of tests noted in the patients with pituitary lesions.

Glucocorticoid withdrawal and TRH tests in patients with Sheehan's syndrome. Fig. 6 depicts the gluco- corticoid withdrawal tests and TSH responses to TRH administration in four patients with Sheehan's syndrome. In every case the glucocorticoid withdrawal test is abnormal, as indicated by the lack of overshoot in TIR and slow return to the base-line release slope. Although all of the patients in this group had abnormal glucocorticoid withdrawal responses, they all responded normally to administration of exogenous TRH, indicating adequate 
pituitary TSH reserve capacity. Thus, these patients display patterns similar to that of the patient with the hypothalamic lesion, depicted in Fig. 5, by exhibiting impaired endogenous TRH reserve, while retaining normal pituitary TSH reserve. Additional evidence for diminished endogenous TRH reserve or transport is the fact that two of the patients in this group were hypothyroid, yet responded normally to TRH stimulation. However, it is also apparent that the euthyroid state can be maintained in the presence of impaired endogenous TRH reserve, since two of the four patients in this study group were euthyroid.

\section{DISCUSSION}

The results of this study indicate that the combined use of the glucocorticoid withdrawal test for endogenous $\mathrm{TRH}$ reserve and the TRH stimulation test for pituitary $\mathrm{TSH}$ reserve allows for differentiation between certain pituitary and suprahypophyseal lesions. Patients with pure pituitary lesions exhibit parallel impairment of both glucocorticoid withdrawal and TRH stimulation tests, in contrast to patients with apparent suprahypophyseal lesions who only demonstrate impaired glucocorticoid withdrawal testing, while maintaining normal $\mathrm{TSH}$ reserve capacity. The numerous recent studies in man attest to the validity of the use of synthetic TRH to assess endogenous TSH reserve. Employing the glucocorticoid withdrawal maneuver also seems to be a valid method for assessing endogenous TRH reserve capacity, as the animal work of Wilber and Utiger (20) and our present study (Fig. 3) provide in vivo evidence for the glucocorticoid suppressive effect on endogenous TRH release. Also, recent work by Reichlin (21) provides evidence that TRH synthetase activity is altered by glucocorticoid administration. Thus the magnitude and rebound of TIR noted following glucocorticoid withdrawal would seem to directly reflect augmented release of endogenous TRH.

It would appear that the four patients with Sheehan's syndrome have diminished endogenous TRH reserve or transport rather than primary pituitary lesions affecting the thyrotroph population. This does not imply that all patients with this disorder have suprapituitary lesions. Fleischer and coworkers (4) for example, have shown that administration of $500 \mu \mathrm{g}$ of synthetic TRH to several patients with Sheehan's syndrome produced no detectable increase in serum TSH levels. Indeed, pituitary necrosis often characterizes the pathologic findings in this disorder (23). On the other hand, it has been shown by Sheehan and Stanfield (24) that the lesion in this disorder may occasionally involve only the vascular supply of the pituitary stalk with secondary pituitary insufficiency. Sheehan (23) also has shown that the pituitary gland is capable of some regeneration and prolifera- tion of the parenchyma following vascular necrosis. The fact that pregnancy had occurred in two of our patients, and also has been reported by others $(25,26)$, adds support to the contention that not a simple destructive lesion of the pituitary had occurred in this group, as in the postcryohypophysectomy patients. It would follow then that other pituitary trophic hormone deficiencies in Sheehan's syndrome may involve impaired hypophysiotrophic hormone reserve or transport capacity.

Despite the apparent discrimination provided by the methods employed in this study, certain inherent limitations are evident. The interpretation of the glucocorticoid withdrawal test is at present qualitative in nature. No firm conclusions regarding the amount of suppression by glucocorticoids and the degree of rebound of TIR following glucocorticoid withdrawal can be made by simple inspection of the graphic data. However, we are currently assessing various measurable parameters in order to quantitate the degree of suppression and rebound. These data will be included in a subsequent report. Presently though, it seems evident that the differences in rebound responses in normal subjects and those in patients with pituitary and suprahypophyseal disorders can be appreciated on a qualitative basis. Another methodological limitation is that several weeks of frequent daily urine collections are required as a part of this study procedure. This tends to be somewhat cumbersome and tedious, therefore limiting its potential clinical usefulness.

Possibly the most interesting finding in this study was that euthyroidism could be maintained in spite of impaired endogenous TRH reserve. This was apparent in the patient with the hypothalamic lesion and in two of the four patients with Sheehan's syndrome. Perhaps the wide distribution of TRH in the anterior and basal portions of the hypothalamus, and the compensating nature of the negative feedback action of thyroid hormone on pituitary release of TSH allows for maintenance of a euthyroid state in the presence of this apparent diminished TRH reserve. Recent studies performed in other euthyroid patients with suspected or demonstrated hypothalamic lesions have revealed similar findings $(27,28)$. Thus a future major application of the TRH stimulation and glucocorticoid withdrawal tests may be in the detection of patients with abnormal endogenous TRH reserve, in whom adequate $\mathrm{TSH}$ reserve and normal peripheral thyroid hormone economy are maintained.

\section{ACKNOWLEDGMENTS}

The authors express their gratitude to Dr. Michael S. Anderson, Abbott Laboratories (North Chicago, Ill.) for the generous supply of synthetic TRH. The authors also wish to thank Misses Josie Jaramillo and Ursula Finck for their excellent technical assistance, and Mrs. Anne Santo for her help in preparing the manuscript. 
This investigation was supported in part by Research Grant AM-11727, General Clinical Research Center Grant RR-43, and Research Fellowship AM-53093 from the National Institutes of Health, Public Health Service.

\section{REFERENCES}

1. Ormston, B. J., R. Garry, R. J. Cryer, G. M. Besser, and R. Hall. 1971. Thyrotrophin-releasing hormone as a thyroid-function test. Lancet. II : 10.

2. Lawton, N. F., R. P. Ekins, and J. D. N. Nabarro. 1971. Failure of pituitary response to thyrotrophin-releasing hormone in euthyroid Graves' disease. Lancet. II: 14.

3. Haigler, E. D., Jr., J. A. Pittman, Jr., J. M. Hershman, and C. M. Baugh. 1971 Direct evaluation of pituitary thyrotropin reserve utilizing synthetic thyrotropin releasing hormone J. Clin. Endocrinol. Metab. 33: 573.

4. Fleischer, N., M. Lorente, J. Kirkland, R. Kirkland, G. Clayton, and M. Calderon. 1972. Synthetic thyrotropin releasing factor as a test of pituitary thyrotropin reserve. J. Clin. Endocrinol. Metab. 34:617.

5. Miyai, K., M. Azukizawa, and Y. Kumahara. 1971. Familial isolated thyrotropin deficiency with cretinism. N. Engl. J. Med. 285: 1034 .

6. Hershman, J. M., and J. A. Pittman, Jr. 1970. Response to synthetic thyrotropin-releasing hormone in man. $J$. Clin. Endocrinol. Metab. 31: 457.

7. Pittman, J. A., Jr., E. D. Haigler, Jr., J. M. Hershman, and C. S. Pittman. 1971. Hypothalamic hypothyroidism. N. Engl. J. Med. 285: 844 .

8. Costom, B. H., M. M. Grumbach, and S. L. Kaplan. 1971. Effect of thyrotropin-releasing factor on serum thyroid-stimulating hormone. J. Clin. Invest. 50: 2219.

9. Nicoloff, J. T., D. A. Fisher, and M. D. Appleman, Jr. 1970. The role of glucocorticoids in the regulation of thyroid function in man. J. Clin. Invest. 49: 1922.

10. Greenwood, F. C., J. Landon, and T. C. B. Stamp. 1966. The plasma sugar, free fatty acid, cortisol, and growth hormone response to insulin. I. In control subjects. $J$. Clin. Invest. $45: 429$.

11. Greenwood, F. C., and W. M. Hunter. 1963. The preparation of ${ }^{131}$ I-labelled human growth hormone of high specific radioactivity. Biochcm. J. 89: 114.

12. Rutherford, E. R., and D. H. Nelson. 1963. Determination of urinary 17-ketogenic steroids by means of sodium metaperiodate oxidation. J. Clin. Endocrinol. Mctab. 23: 533.

13. Klinefelter, H. F., Jr., F. Albright, and G. C. Griswold. 1943. Experience with a quantitative test for normal or decreased amounts of follicle stimulating hormone in the urine in endocrinological diagnosis. J. Clin. Endocrinol. Metab. $3: 529$.

14. Odell, W. D., J. F. Wilber, and R. D. Utiger. 1967. Studies of thyrotropin physiology by means of radioimmunoassay. Recent Prog. Horm. Res. 23: 47.

15. Murphy, B. E. P., and C. J. Pattee. 1964. Determination of thyroxine utilizing the property of proteinbinding. J. Clin. Endocrinol. Metab. 24: 187.

16. Sterling, K., and M. A. Brenner. 1966. Free thyroxine in human serum: simplified measurement with the aid of magnesium precipitation. J. Clin. Invest. 45: 153.

17. Nicoloff, J. T. 1970. A new method for the measurement of thyroidal iodine release in man. J. Clin. Invest. 49: 1912

18. Gross, H. A., M. D. Appleman, Jr., and J. T. Nicoloff. 1971. Effect of biologically active steroids on thyroid function in man. J. Clin. Endocrinol. Metab. 33: 242.

19. Nicoloff, J. T. 1970. A new method for the measurement of acute alterations in thyroxine deiodination rate in man. J. Clin. Invest. $49: 267$.

20. Wilber, J. F., and R. D. Utiger. 1969. The effect of glucocorticoids on thyrotropin secretion. J. Clin. Invest. 48: 2096.

21. Reichlin, S. 1972. Eli Lilly Lecture, IV International Congress of Endocrinology, Washington, D. C., June 1972.

22. Snyder, P. J., and R. D. Utiger. 1972. Response to thyrotropin releasing hormone $(\mathrm{TRH})$ in normal man. J. Clin. Endocrinol. Metab. 34: 380.

23. Sheehan, H. L. 1965. The repair of post-partum necrosis of the anterior lobe of the pituitary gland. Acta Endocrinol. 48: 40 .

24. Sheehan, H. L., and J. P. Stanfield. 1961. The pathogenesis of post-partum necrosis of the anterior lobe of the pituitary gland. Acta Endocrinol. 37: 479.

25. Jackson, I. M. D., W. G. Whyte, and M. M. Garrey. 1969. Pituitary function following uncomplicated pregnancy in Sheehan's syndrome. J. Clin. Endocrinol. Me tab. $29: 315$.

26. Martin, J. E., P. C. MacDonald, and N. M. Kaplan. 1970. Successful pregnancy in a patient with Sheehan's syndrome. N. Engl. J. Med. 282: 425.

27. Singer, P. A., and J. T. Nicoloff. 1972. TSH and TRH reserve tests in hypothalamic and pituitary disorders in man. Clin. Res. 20: 220. (Abstr.)

28. Singer, P. A., and J. T. Nicoloff. 1972. A new method for differentiating between hypothalamic and pituitary disorders in man. Clin. Res. 20: 440. (Abstr.) 